\title{
Catálogo provisional de los odonatos (Insecta, Odonata) de la ZEC Txingudi-Bidasoa (Gipuzkoa, País Vasco, España).
}

Provisional Catalogue of Odonates in the Txingudi-Bidasoa Special Area of Conservation (Gipuzkoa, Basque Country, Spain).

Iñaki Mezquita-Aranburu ${ }^{1}$

漠

\section{Resumen}

En este trabajo se elabora el catálogo provisional de los odonatos presentes en la ZEC Txingudi-Bidasoa perteneciente a la Red Natura 2000, en base a los datos recogidos entre 2007 y 2017, así como una revisión bibliográfica de las citas anteriores. Se catalogan las 27 especies de odonatos observadas hasta el año 2017 (12 zigópteros y 15 anisópteros), remarcando la provisionalidad de este catálogo dada la previsible aparición o descubrimiento de nuevas especies aún no localizadas.

Palabras clave: Plaiaundi, Marismas, Anisoptera, Zygoptera, Red Natura 2000.

\begin{abstract}
The present article sets out to compile a provisional catalogue of the odonates present in the Txingudi-Bidasoa SAC, which belongs to the Natura 2000 network, based on data collected between 2007 and 2017, as well as a bibliographical review of the previous references. The catalogue includes the 27 species of odonates observed up to 2017 (12 Zygoptera and 15 Anisoptera). We should like to point out that the aforementioned catalogue is provisional, given that it is likely that a number of new species have yet to be discovered.
\end{abstract}

Key words: Plaiaundi, Marshlands, Anisoptera, Zygoptera, Natura 2000 network.

\footnotetext{
1 Sociedad de Ciencias Aranzadi Departamento de Entomología Paseo de Zorroaga 11, 20004 Donostia-San Sebastián (Spain) 


\section{Laburpena}

Lan honetan Natura 2000 Sarean barne dagoen Txingudi-Bidasoa KBEan 2007 eta 2017 urteen tartean behatu diren odonatu espezieen katalogoa jaso da, baita espazio honetako odonatu aipamenen errebisio bibliografikoa erantsi da. 2017 urtera arte aurkitu diren 27 odonatu espezieen katalogoa jaso da (12 zigoptero eta 15 anisoptero), bilduma honen behin-behinekotasuna azpimarratuaz, balitekeelako espezie berriak agertzea edo topatzea, oraindik behatu ez direnak.

Gako hitzak: Plaiaundi, Padurak, Anisoptera, Zygoptera, Natura 2000 Sarea.

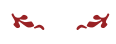

\section{Introducción}

A la vista de la importancia del espacio Txingudi-Bidasoa como corredor natural entre la Península Ibérica y la Europa continental, aprovechando el decaimiento en altitud en esta zona de los Pirineos y la Cordillera Cantábrica, este enclave fue propuesto para su inclusión en la Red Natura como Lugar de Importancia Comunitaria (LIC) en el año 1997, mediante reunión del Consejo del Gobierno Vasco del 23 de diciembre. Esta propuesta se materializó mediante el Decreto 356/2013 del 4 de junio de 2013.

El catálogo de especies citadas en Gipuzkoa hasta la fecha comprende un total de 45 especies (Paz \& Conesa, 2017). Se trata de una diversidad de especies semejante a la de sus territorios limítrofes: 51 especies en Álava, 42 en Bizkaia, 49 en La Rioja y 44 en Cantabria (Gainzarain, 2018, Prunier et al., 2015). Concretamente, para la ZEC Txingudi-Bidasoa existe una escasez de registros sobre la fauna odonatológica, consistente en algunas citas esporádicas y aisladas, algunas de ellas sin precisar localidades concretas salvo el municipio, que suman 19 especies en total (Ocharan Larrondo, 1987; Mezquita et al., 2011; Mezquita \& Ocharan, 2012). Ante esta falta de información, se elabora el presente trabajo con el objetivo de realizar el primer catálogo de odonatos para la ZEC Txingudi-Bidasoa.

La ZEC Txingudi-Bidasoa se localiza en el extremo oriental del litoral del País Vasco, en el Territorio Histórico de Gipuzkoa. Está integrada fundamentalmente por el río Bidasoa, incluidas sus zonas de marismas, islas y márgenes, en el tramo comprendido entre la ZEC "Aiako Harriak/Peñas de Aia" y Plaiaundi (términos municipales de Irún y Hondarribia) y por la regata Jaizubia y sus márgenes, incluyendo parte de su vega y marismas adyacentes.

Su superficie abarca un total de 277,05 ha., de las cuales 139,5 corresponden al ámbito designado como LIC, y las 138 ha. restantes al ámbito designado como ZEPA. Esta superficie se reparte entre los municipios de Irun y Hondarribia, correspondiendo al municipio de Hondarribia un total de 94,34 ha. y 182,76 ha. al de Irun. 
El catálogo se ha elaborado en base a tres fuentes: revisión bibliográfica de las citas previamente publicadas, muestreos del autor y citas recogidas en la Plataforma ornitho.eus.

Se ha consultado la bibliografía existente para la zona y se han incluido en el catálogo las citas bibliográficas previas (si las hubiera).

En la Tabla I se recogen las localidades visitadas. Las visitas hasta las campañas de 2015 y 2016 no han seguido un modelo preestablecido, ni han sido programadas en forma de transectos, sino que se han basado en visitas esporádicas a las zonas más sensibles cuando la climatología ha sido favorable y otros compromisos las han hecho posibles. Por ello, se da el caso de descompensaciones evidentes entre unas campañas y otras en cuanto a esfuerzo de muestreo por parte del autor (2007: 2 visitas, 2008: 0 visitas, 2009: 3 visitas, 2010: 2 visitas, 2011: 10 visitas, 2012: 5 visitas, 2013: 1 visita, 2014: 0 visitas, 2015: 2 visitas, 2016: 2 visitas). Los registros del autor proceden de observaciones in situ de los ejemplares. Cuando ha sido posible, se han tomado de imágenes de los mismos con cámaras digitales, sin sacrificio de los animales. En la toma de fotografías, se ha hecho especial hincapié en la importancia de plasmar aquellos detalles anatómicos en los se fundamenta la determinación específica (venación alar y órganos sexuales, mayoritariamente), así como de los ejemplares completos (posados y/o en vuelo). El archivo fotográfico del autor consta de más de 6.000 imágenes catalogadas y clasificadas por localidad, fecha y especie. Se han utilizado

\begin{tabular}{|c|l|l|l|l|c|}
\hline Localidad & Denominación & \multicolumn{1}{|c|}{ Tipo de hábitat } & Municipio & UTM & Altitud \\
\hline 1 & Hondarribia & Regatas & Hondarribia & WN9699 & $22 \mathrm{~m}$ \\
\hline 2 & $\begin{array}{l}\text { Marismas de } \\
\text { Txingudi-Jaizubia }\end{array}$ & Regatas y balsas & Hondarribia & WP9600 & $0 \mathrm{~m}$ \\
\hline 3 & $\begin{array}{l}\text { Marismas de } \\
\text { Txingudi-Plaiaundi }\end{array}$ & $\begin{array}{l}\text { Lagunas de } \\
\text { agua dulce }\end{array}$ & Irún & WP9700 & $0 \mathrm{~m}$ \\
\hline 5 & Alunda & $\begin{array}{l}\text { Río Bidasoa y } \\
\text { terrenos colindantes }\end{array}$ & Irún & XN0198 & $5 \mathrm{~m}$ \\
\hline 6 & Lastaola & $\begin{array}{l}\text { Río Bidasoa y } \\
\text { terrenos colindantes }\end{array}$ & Irún & XN0297 & $6 \mathrm{~m}$ \\
\hline
\end{tabular}

Tabla 1.- Localidades visitadas.

Table 1.- Locations visited. 
cámaras digitales de alta resolución, equipadas con objetivos de macrofotografía y teleobjetivos, también fuentes adicionales de luz, así como distintos soportes y dispositivos. A estas imágenes hay que añadir las realizadas por el voluntariado, publicadas algunas de ellas en la Plataforma ornitho.eus.

Durante los años 2015 y 2016 se han realizado en el Parque Ecológico de Plaiaundi distintos seminarios de cara a la formación de las personas interesadas en llevar a cabo labores de seguimiento de odonatos. En ellas, además de nociones generales sobre estos insectos, se ha instruido al personal asistente en la identificación en el campo de las distintas especies, haciendo especial hincapié en las especies presentes en la zona, así como de especies de territorios limítrofes. Estas iniciativas han dado lugar a la formación de un grupo de voluntarios en Plaiaundi (en adelante GVP) que está realizando un seguimiento exhaustivo de la zona, incluyendo sus registros en la Plataforma ornitho.eus.

En ocasiones, hay varias citas para un mismo lugar y localidad, debido a registros de varios observadores.

Los resultados se indican en forma de catálogo. Se recogen en él: las citas previas; las observaciones realizadas, con fecha y localidad; la abundancia de los individuos observados, y el sexo de los mismos cuando estaba registrado.

Las citas hasta el año 2012 (incluido) están recogidas en Odonatos de Gipuzkoa (Mezquita \& Ocharan, 2012) y las de los años 2013 y 2014 proceden del autor.

\section{LISTA DE ODONATOS DE LA ZEC TXINGUDI-BIDASOA}

\section{Suborden Zygoptera}

\section{Familia Calopterygidae}

1. Calopteryx haemorrhoidalis (Vander Linden, 1825)

Citas bibliográficas: Mezquita \& Ocharan para Jaizubia (2012).

Localidades:

2 (04.09.2016, 10 ejemplares).

2. Calopteryx xanthostoma (Charpentier, 1825)

No existen citas previas.

Localidades:

3 (12.09.2016, 1 macho) 


\section{Familia Coenagrionidae}

3. Coenagrion scitulum (Rambur, 1842)

Citas bibliográficas: Mezquita (2015)

Localidades:

3 (13.06.2015, 2 machos; 21.06.2016, 100 ejemplares; 22.06.2016, 8 ejemplares; 23.06.2016, 4 ejemplares; 23.06.2016, 2 ejemplares).

4.Enallagma cyathigerum (Charpentier, 1840)

Citas bibliográficas: Mezquita \& Ocharan (2012)

Localidades:

3 (21.04.2013, 2 machos; 05.06.2016, 1 macho y 1 hembra; 12.06.2016, 1 macho; 22.06.2016, 6 machos; 23.06.2016, 20 machos; 23.06.2016, 6 machos; 27.06.2016, 1 macho; 22.07.2016, 1 macho; 22.07.2016, 1 macho; 26.07.2016, 1 macho; 14.08.2016, 3 machos).

\section{Erythromma viridulum (Charpentier, 1840)}

Citas bibliográficas: Mezquita et al. (2011), Mezquita \& Ocharan (2012) Localidades:

2 (09.06.2016, 2 machos; 28.06.2016, 1 macho y 1 hembra; 26.07.2016, 5 ejemplares); 3 (24.07.2015, 1 ejemplar; 05.06.2016, 1 ejemplar; 12.06.2016, 8 ejemplares; 20.06.2016, 8 ejemplares; 21.06.2016, 20 ejemplares; 22.06.2016, 6 ejemplares; 23.06.2016, 1 macho y 1 hembra; 23.06.2016, 2 ejemplares; 27.06.2016, 1 macho; 30.06.2016, 2 machos; 09.07.2016, 5 ejemplares; 16.07.2016, 12 ejemplares; 18.06.2016, 6 ejemplares; 25.07.2016, 1 macho; 26.07.2016, 10 ejemplares; 14.08.2016, 2 ejemplares; 14.08.2016, 5 ejemplares; 12.09.2016, 5 ejemplares).

\section{Ischnura elegans (Vander Linden, 1820)}

Citas bibliográficas: Mezquita et al. (2011), Mezquita \& Ocharan (2912), Mezquita (2014)

Localidades:

1 (26.05.2016, 1 macho; 05.06.2016, 3 machos y 1 hembra; 09.06.2016, 2 hembras; 19.06.2016, 1 macho y 1 hembra); 2 (09.06.2016, 3 machos; 19.06.2016, 3 machos); 3 (21.04.2013, 20 machos y 15 hembras; 25.04.2015, 25 ejemplares; 13.06.2015, 1 macho; 13.06.2016, 60 machos y 40 hembras; 14.06.2015, 6 ejemplares; 14.06.2015, 1 macho; 21.06.2015, 30 ejemplares; 24.07.2015, 1 macho; 29.04.2016, 11 ejemplares; 01.06.2016, 1 macho; 03.06.2016, 1 macho y 1 hembra; 04.06.2016, 6 ejemplares; 04.06.2016, 10 ejemplares; 05.06.2015, 4 ejemplares; 
05.06.2016, 10 ejemplares; 12.06.2016, 10 ejemplares; 12.06.2016, 10 ejemplares; 14.06.2016, 3 ejemplares; 15.06.2016, 2 ejemplares; 16.06.2016, 5 ejemplares; 17.06.2016, 1 ejemplar; 18.06.2016, 6 ejemplares; 19.06.2016, 1 macho; 20.06.2016, 10 ejemplares; 21.06.2016, 10 ejemplares; 23.06.2016, 5 ejemplares; 24.06.2016, 9 machos y 1 hembra; 25.06.2016, 7 machos y 1 hembra; 26.06.2016, 10 ejemplares; 27.06.2016, 2 machos y 1 hembra; 30.06.2016, 5 machos y 5 hembras; 09.07.2016, 10 ejemplares; 16.07.2016, 20 ejemplares; 22.07.2016, 100 ejemplares; 22.07.2016, 50 ejemplares; 23.07.2016, 20 ejemplares; 23.07.2016, 50 ejemplares; 24.07.2016, 30 ejemplares; 25.07.2016, 10 ejemplares; 26.07.2016, 10 ejemplares; 26.07.2016, 1 macho y 1 hembra; 07.08.2016, 30 machos y 13 hembras; 14.08.2016, 10 ejemplares; 18.08.2016, 7 machos; 06.09.2016, 2 ejemplares; 11.09.2016, 2 ejemplares; 11.09.2016, 1 ejemplar; 12.09.2016, 4 ejemplares; 17.09.2016, 4 machos; 21.09.2016, 4 ejemplares; 22.09.2016, 3 machos; 23.09.2016, 2 machos y 1 hembra; 26.09.2016, 1 hembra; 02.10.2016, 2 ejemplares); 6 (21.09.2016, 1 macho y 1 hembra).

\section{Ischnura pumilio (Charpentier, 1825)}

Citas bibliográficas: Mezquita et al. (2011), Mezquita \& Ocharan (2012), Mezquita 2014).

Localidades:

3 (21.04.2013, 1 macho; 20.09.2016, 1 macho; 23.09.2016, 2 machos y 1 hembra 23.09.2016, 3 ejemplares; 02.10.2016, 2 ejemplares); 6 (24.08.2016, 3 machos y 1 hembra; 15.09.2016, 15 machos y 4 hembras; 02.10.2016, 3 machos).

8. Ceriagrion tenellum (de Villers, 1789)

Citas bibliográficas: Mezquita et al. (2012)

Localidades:

3 (07.06.2016, 1 ejemplar); 4 (30.08.2016, 8 machos y 1 hembra); 6 (24.08.2016, 2 machos).

\section{Familia Lestidae}

9. Lestes barbarus (Fabricius, 1798)

No existen citas previas.

Localidades:

2 (26.07.2016, 1 hembra) 
10.Lestes virens (Charpentier, 1825)

No existen citas previas.

Localidades:

3 (11.09.2016, 1 macho).

11. Chalcolestes viridis (Vander Linden, 1825)

Citas bibliográficas: Mezquita et al. (2011)

Localidades:

2 (26.07.2016, 1 macho; 11.09.2016, 1 ejemplar); 3 (01.12.2016, 1 hembra; 10.10.2015, 4 ejemplares; 03.06.2016, 1 macho y 1 hembra; 03.06.2016, 2 ejemplares; 04.06.2016, 1 hembra; 04.06.2016, 1 macho y 1 hembra; 05.06.2016, 1 macho; 05.06.2016, 1 macho; 14.06.2016, 1 ejemplar; 22.06.2016, 1 macho y 1 hembra; 23.06.2016, 1 macho; 25.06.2016, 1 macho; 16.07.2016, 1 macho; 16.07.2016, 1 macho; 26.07.2016, 1 macho; 07.08.2016, 2 ejemplares; 06.09.2016, 2 ejemplares; 11.09.2016, 1 ejemplar; 14.09.2016, 1 macho y 1 hembra; 21.09.2016, 3 machos y 2 hembras; 22.09.2016, 2 machos y 2 hembras; 24.09.2016, 2 machos; 26.09.2016, 2 machos; 02.10.2016, 5 machos y 1 hembra); 4 (30.08.2016, 1 macho); 6 (21.09.2016, 1 macho).

12.Sympecma fusca (Vander Linden, 1820)

Citas bibliográficas: Mezquita et al. (2011), Mezquita \& Ocharan (2012)

\section{Suborden Anisoptera}

\section{Familia Aeshnidae}

13.Anax imperator Leach 1815

Citas bibliográficas: Mezquita et al. (2011), Mezquita \& Ocharan (2012) Localidades:

1 (07.08.2016, 1 ejemplar); 2 (12.06.2016, 2 ejemplares; 28.06.2016, 1 macho); 3 (13.06.2015, 1 ejemplar; 13.06.2015, 1 hembra; 21.06.2015, 3 machos y 1 hembra; 25.06.2015, 1 ejemplar; 03.06.2016, 1 macho; 05.06.2016, 4 ejemplares; 05.06.2016, 1 macho y 1 hembra; 12.06.2016, 2 ejemplares; 12.06.2016, 2 ejemplares; 14.06.2016, 1 ejemplar; 20.06.2016, 2 machos y 1 hembra; 21.06.2016, 2 machos y 1 hembra; 23.06.2016, 5 ejemplares; 23.06.2016, 1 macho y 1 hembra; 26.06.2016, 1 ejemplar; 27.06.2016, 1 ejemplar; 27.06.2016, 3 machos; 30.06.2016, 3 machos y 1 hembra; 09.07.2016, 3 machos y 1 hembra; 16.07.2016, 10 ejemplares; 18.07.2016, 2 ejemplares; 22.07.2016, 1 ejemplar; 25.07.2016, 1 ejemplar; 
26.07.2016, 6 ejemplares; 26.07.2016, 1 macho; 26.07.2016, 1 hembra; 14.08.2016, 2 machos; 14.08.2016, 5 ejemplares; 11.09.2016, 2 ejemplares; 12.09.2016, 3 ejemplares; 14.09.2016, 3 ejemplares; 02.10.2016, 1 macho).

14.Anax parthenope (Selys 1839)

Citas previas: Mezquita et al. (2011), Mezquita \& Ocharan (2012) Localidades:

3 (21.06.2015, 4 ejemplares; 25.06.2015, 1 ejemplar; 04.07.2015, 1 ejemplar; 05.06.2016, 1 macho; 20.06.2016, 2 ejemplares; 21.06.2016, 2 machos y 1 hembra; 22.06.2016, 1 macho; 23.06.2016, 5 ejemplares; 25.06.2016, 1 ejemplar; 27.06.2016, 1 macho; 30.06.2016, 2 ejemplares; 09.07.2016, 3 ejemplares; 16.07.2016, 5 ejemplares; 18.07.2016, 1 ejemplar; 26.07.2016, 2 ejemplares; 22.09.2016, 1 macho; 02.10.2016, 1 macho).

15.Anax ephippiger (Burmeister, 1839)

Citas bibliográficas: Mezquita et al. (2011), Mezquita \& Ocharan (2012)

16.Aeshna cyanea (Müller, 1764)

Citas bibliográficas: Ocharan Larrondo (1987)

Localidades:

3 (21.09.2015, 2 ejemplares).

17.Aeshna mixta Latreille 1805

Citas bibliográficas: Mezquita (2014)

Localidades:

3 (13.10.2015, 4 machos; 08.10.2015, 2 ejemplares; 10.10.2015, 10 ejemplares; 28.10.2015, 6 ejemplares; 28.10.2015, 2 ejemplares; 04.11.2015, 2 ejemplares; 14.09.2016, 1 macho; 21.09.2016, 2 machos; 22.09.2016, 3 machos, 23.09.2016, 1 ejemplar; 24.09.2016, 3 ejemplares; 26.09.2016, 6 ejemplares; 02.10.2016, 2 ejemplares; 02.10.2016, 2 machos y 1 hembra; 31.10.2016, 2 ejemplares); 6 (15.09.2016, 2 machos; 02.10.2016, 1 macho).

18. Boyeria Irene McLachlan, 1896

No existen citas previas.

Localidades:

5 (30.08.2016, 2 ejemplares). 


\section{Familia Libellulidae}

19. Libellula quadrimaculata Linnaeus, 1758

Citas bibliográficas: Mezquita et al. (2011), Mezquita \& Ocharan (2012)

Localidades:

3 (12.06.2016, 1 macho; 12.06.2016, 1 macho; 21.06.2016, 1 ejemplar; 23.06.2016, 1 macho).

20. Orthetrum albistylum (Selys, 1848)

Citas bibliográficas: Mezquita et al. (2011), Mezquita \& Ocharan (2012)

Localidades:

2 (28.06.2016, 1 macho); 3 (21.06.2016, 1 macho y 1 hembra; 22.06.2016, 1 macho; 18.07.2016, 1 macho; 24.08.2016, 1 macho).

\section{Orthetrum brunneum (Fonscolombe, 1837)}

Citas bibliográficas: Mezquita et al. (2011), Mezquita \& Ocharan (2012)

Localidades:

6 (24.08.2016, 2 machos y 1 hembra; 04.09.2016, 1 macho; 21.09.2016, 1 macho).

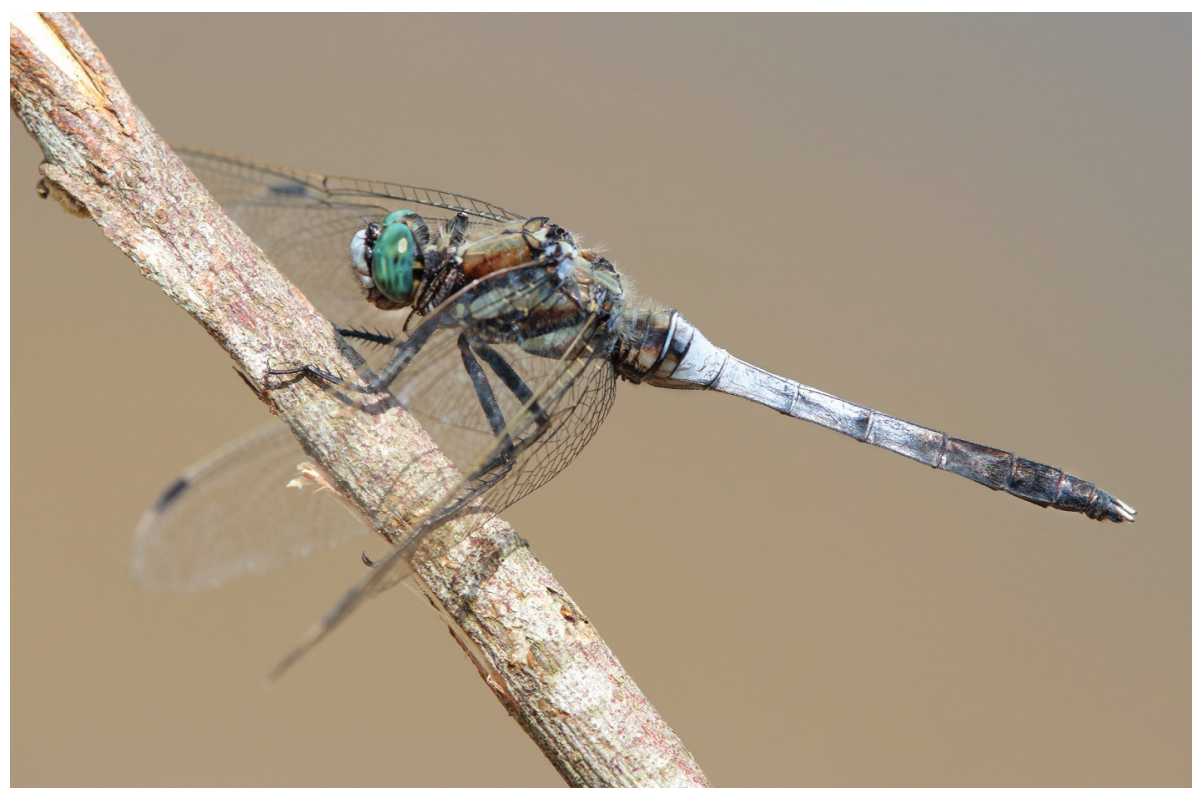


22. Orthetrum cancellatum (Linnaeus, 1758)

Citas bibliográficas: Mezquita et al. (2011), Mezquita \& Ocharan (2012)

Localidades:

2 (28.06.2016, 1 macho; 26.07.2016, 3 machos y 1 hembra; 11.09.2016, 2 machos); 3 (21.04.2013, 1 macho y 1 hembra; 05.06.2016, 1 ejemplar; 22.06.2016, 1 macho; 23.06.2016, 3 machos y 2 hembras; 23.06.2016, 1 macho; 30.06.2016, 1 macho; 26-07.2016, 1 macho; 14.08.2016, 2 machos y 2 hembras; 14.08.2016, 1 macho; 22.09.2016, 1 macho; 26.09.2016, 1 macho; 02.10.2016, 1 hembra).

\section{Orthetrum coerulescens (Fabricius, 1798)}

Citas bibliográficas: Mezquita (2014) (sin especificar sexo ni abundancia) Localidades:

4 (30.08.2016, 14 machos y 1 hembra; 30.08.2016, 1 macho); 5 (30.08.2016, 11 machos); 6 (11.09.2015, 1 ejemplar; 24.08.2016, 12 machos y 2 hembras; 04.09.2016, 3 ejemplares; 15.09.2016, 3 machos; 21-09-2016, 3 machos).

\section{Sympetrum fonscolombii (Selys, 1840)}

Citas bibliográficas: Mezquita et al. (2011), Mezquita \& Ocharan (2012) Localidades:

3 (21.04.2013, 1 macho; 05.06.2015, 1 ejemplar; 20.07.2015, 1 ejemplar; 24.07.2015, 2 ejemplares; 05.06.2016, 6 ejemplares; 05.06.2016, 1 macho; 23.06.2016, 1 ejemplar; 23.06.2016, 4 machos; 27.06.2016, 2 machos y 1 hembra; 30.06.2016, 1 macho y 1 hembra; 16.07.2016, 4 ejemplares; 18.07.2016, 2 machos y 1 hembra; 26.07.2016, 10 ejemplares; 26.07.2016, 1 hembra; 14.08.2016, 1 macho; 11.09.2016, 2 machos y 1 hembra; 23.09.2016, 15 ejemplares; 26.09.2016, 3 ejemplares; 02.10.2016, 1 ejemplar; 02.10.2016, 7 ejemplares); 6 (21.09.2016, 2 machos y 1 hembra; 02.10.2016, 2 machos y 1 hembra).

\section{Sympetrum striolatum (Charpentier, 1840)}

Citas bibliográficas: Mezquita et al. (2011), Mezquita \& Ocharan (2012) Localidades:

2 (19.06.2016, 1 hembra); 13.10.2015, 2 machos y 1 hembra; 17.11.2015, 3 ejemplares; 02.12.2015, 3 machos y 1 hembra; 06.12.2015, 1 macho; 07.12.2015, 2 machos; 12.12.2015, 1 ejemplar; 12.12.2015, 1 ejemplar; 18.12.2015, 1 ejemplar; 23.12.2015, 1 ejemplar; 22.09.2016, 2 machos; 26.09.2016, 1 ejemplar; 31.10.2016, 5 ejemplares; 24.11.2016, 4 machos y 2 hembras; 01.12.2016, 2 machos y 1 hembra; 06.12.2016, 10 machos y 1 hembra; 07.12.2016, 9 machos y 4 hembras); 6 (21.09.2016, 8 machos y 2 hembras). 
26. Crocothemis erythraea (Brullé, 1832)

Citas bibliográficas: Mezquita et al. (2011), Mezquita \& Ocharan (2012) Localidades:

1 (07.08.2016, 1 macho); 2 (28.06.2016, 2 machos; 26.07.2016, 1 macho); 3 (25.06.2015, 1 macho; 03.06.2016, 3 ejemplares; 05.06.2016, 1 macho; 20.06.2016, 2 machos y 1 hembra; 21.06.2016, 3 machos y 1 hembra; 23.06.2016, 3 machos y 1 hembra; 27.06.2016, 2 machos; 30.06.2016, 2 machos).

27. Trithemis annulata (Palisot de Beauvois, 1807)

Citas bibliográficas: Mezquita (2014) (sin especificar sexo ni abundancia) Localidades:

3 (22.09.2016, 1 macho; 24.09.2016, 1 hembra).

Fig. 3.- Trithemis annulata hembra

Fig. 3.- Trithemis annulata female

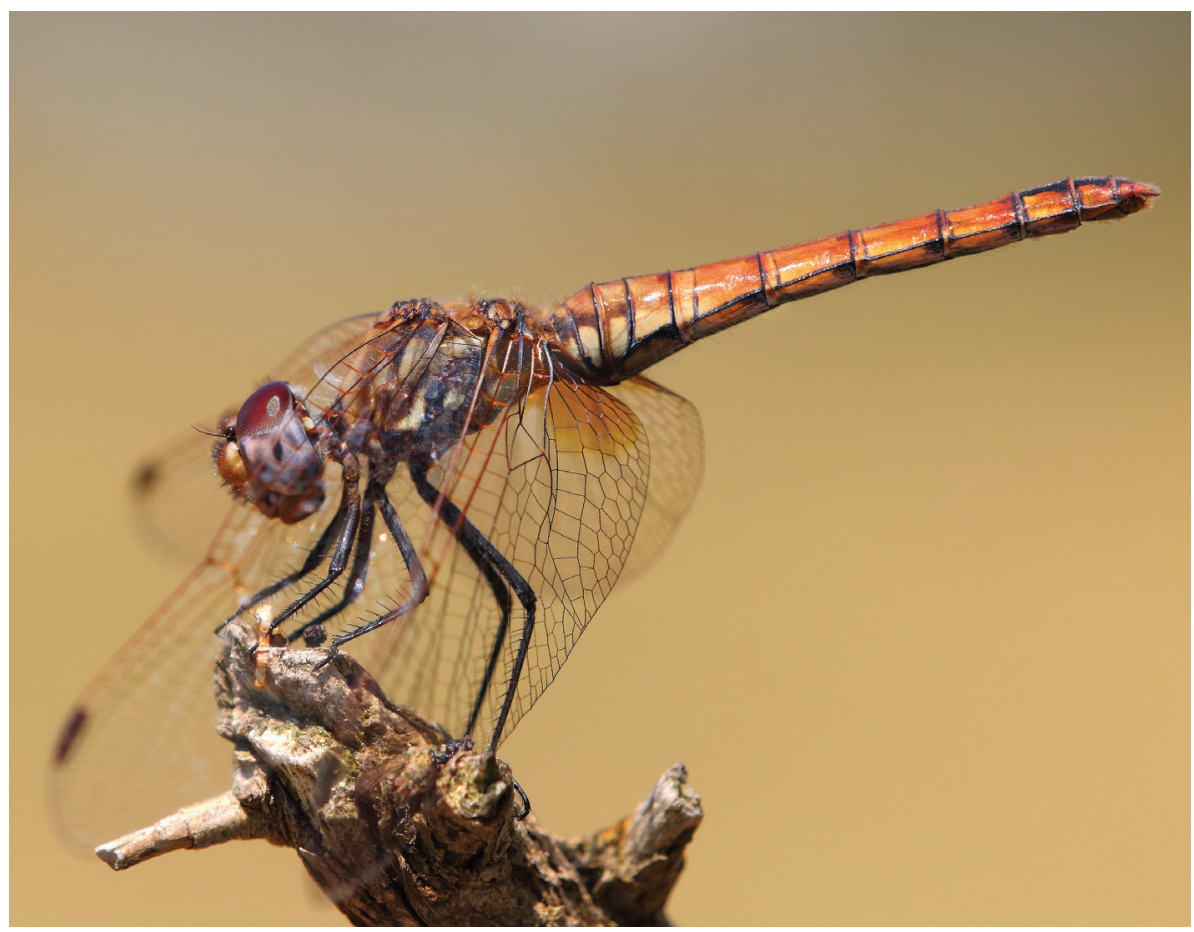




\section{Conclusiones}

En el área estudiada, se produjo la primera cita para la península ibérica de Orthetrum albistylum, la primera para la cornisa cantábrica de Anax ephippiger y la primera para la CAPV de Trithemis annulata. Aunque, en el caso de estas tres especies, no exista constancia de éxito reproductivo (exuvias o emergencias) dentro de la ZEC TxingudiBidasoa, a pesar de haberse observado cópulas y puestas en dos de ellas: A. ephippiger (Mezquita-Aranburu \& Ocharan, 2012) y T. annulata (Otaegi, com. pers.). Además, se han citado especies poco frecuentes en la CAPV, como es el caso del zigóptero Ischnura elegans.

Las citas previas a este trabajo, en relación al ámbito geográfico que nos ocupa, comienzan con Ocharan Larrondo (1987) que cita Aeshna cyanea para la localidad de Fuenterrabía (Hondarribia). Mezquita-Aranburu et al. (2011) citan 16 especies más para el ámbito de Plaiaundi (Ischnura elegans, Ischnura pumilio, Enallagma cyathigerum, Ceriagrion tenellum, Chalcolestes viridis, Sympecma fusca, Anax parthenope, Anax imperator, Anax ephippiger -citada por primera vez para la cornisa cantábrica, Libellula quadrimaculata, Orthetrum albistylum citada por primera vez para la península ibérica-, Orthetrum brunneum, Orthetrum cancellatum, Sympetrum striolatum, Sympetrum fonscolombii y Crocothemis erythraea). En 2012, Mezquita \& Ocharan añaden 2 especies más (Erythromma viridulum y Calopteryx haemorrhoidalis), quedando entonces los registros históricos en 19 especies que, con la actualización del presente catálogo, se elevan a 27 especies. Se trata de un considerable número de especies (ya que supera el $58 \%$ de las citadas en total en el Territorio Histórico de Gipuzkoa). No cabe duda de que dinámicas de seguimiento como la actual, en un entorno del interés y potencialidad de esta ZEC, aportarán en las próximas campañas nuevas incorporaciones a este catálogo provisional.

\section{Agradecimientos}

A Mikel Etxaniz, Alberto Luengo y todo el personal de Ekoetxea Txingudi por el apoyo, colaboración y entusiasmo que han puesto a lo largo de todos estos años en el conocimiento y conservación de los odonatos. A Joseba Otaegi y al grupo de voluntarios (Víctor Marugán, Itziar Gutiérrez, Juncal Lucas, Ricardo Lareo, Alfredo Herrrero, David Santamaría y Begoña Nogueiras) que desde la Plataforma ornitho.eus tantas y tan interesantes observaciones están realizando estos últimos años. Sin su labor, constante y desinteresada, el futuro del conocimiento sobre los odonatos de este entorno y su posterior protección sería mucho más oscuro. A Alberto Castro, Antonio Torralba Burrial y José Antonio Gainzarain por sus valiosas aportaciones que han contribuido a mejorar sensiblemente este trabajo. 


\section{Bibliografía}

Boudot, J.P., Kalkman V.J., Azpilicueta Amorín, M., Bogdanovich, T, Cordero Rivera, A., Degrabiele, G., Domanget, J.L., Ferreira, S., Garrigós, B., Jovic, M., Kotarac, M., Lopau, W., Massrinov, M., Mihokovic, N., Riservato, E., Samraoui, B., Schneider, W. 2009. Atlas of the Odonata of the Mediterranean and North Africa. Libellula, Suppl. 9: 1-256.

Gainzarain, J.A. 2018. Atlas de las libélulas de Álava. Diputación Foral de Álava. Vitoria-Gasteiz.

Gainzarain, J.A., Ocharan, F.J., Mezquita, I. 2013. Catálogo de los odonatos (Insecta: Odonata) de Álava, norte de España. Bol. Soc. Entomol. Aragonesa 53: 173-185.

Klaas-Douwe B. Dijkstra, 2006. Guía de campo de las libélulas de España y Europa. Editorial Omega. Barcelona.

Medidas de conservación de la ZEC ES2120018 TXINGUDI BIDASOA y de la ZEPA ES0000243 TXINGUDI. 2013. Dirección de Medio Natural y Planificación Ambiental, Departamento de Medio Ambiente y Política Territorial. Disponible en:

http://www.ingurumena.ejgv.euskadi.eus/contenidos/informacion/zec/es_natura/adjuntos/txi ngudi.pdf.

Mezquita-Aranburu, I. 2009. Gipuzkoako odonatuak - Odonatos de Gipuzkoa. Diputación Foral de Gipuzkoa. Donostia-San Sebastián.

Mezquita-Aranburu, I. 2012. Libélulas de Bizkaia. BBK. Bilbao.

Mezquita-Aranburu, I., Ocharan, F.J. 2012. Odonatos de Gipuzkoa, Munibe Cienc. Nat. 60: 51-75.

Mezquita-Aranburu, I., Torralba-Burrial, A. 2015. Primera cita de Onychogomphus forcipatus forcipatus (Linnaeus, 1758) (Odonata, Gomphidae) para la Península Ibérica, Bol. SEA 57: 365-366.

Mezquita-Aranburu, I., Torralba, A. Ocharan, F.J. 2011. Primera cita de Orthetrum albistylum (Selys, 1848) (Odonata, Libellulidae) para la Península Ibérica, Bol. Asoc. Esp. Ent. 35: 519-523.

Mezquita-Aranburu, I. 2014. Trithemis annulata Plaiaundin. Txingudiko Paduren Albistegia 56: 2-3.

Prunier, F., Brotóns, M., Cabana, M., Campos, F., Casanueva, P., Chelmick, D., Cordero Rivera, A., Díaz Martínez, C., Evangelio, J.M., Gainzarain, J.A., García-Moreno, J., Lockwood, M., de los Reyes, L., Mañani, J., Mezquita-Aranburu, I., Muddeman, J., Ocharan, F.J., Otero Pérez, F., Prieto Lillo, E., Requena, C., Ripoll, J., Rodríguez Luque, F., Rodríguez, P., Romeo, A., Salcedo, J., Salvador Vilariño, V., Sánchez Balibrea, J., Tamajón Gómez, R, Torralba Burrial, A., Tovar, C., Winter, P., Zaldívar, R. 2015. Actualización del inventario provincial de Odonatos de España peninsular e Islas Baleares. Boletín ROLA 6: 59-84.

Saloña-Bordas, M.J., Ocharan, F.J. 1984. Odonatos de Vizcaya. 2. Anisópteros. Cuad. Investig. Biol. 6: 1-10. 
Paz, L., Conesa, M.A. 2017. Primera cita y confirmación de reproducción de Gomphus vulgatissimus (Linnaeus, 1758) (Odonata : Gomphidae) en Gipuzkoa (País Vasco, España). Munibe, Cienc. Nat. 65: 141-144.

Fecha de recepción/Date of reception: 23/04/2018

Fecha de aceptación/Date of acceptance: 24/09/2018

Editor Asociado/Associate editor: Alberto Castro 